\title{
Acute Hemorrhagic Leukoencephalitis with COVID-19 Coinfection
}

\author{
Raman Sharma $^{1} \cdot$ Chandana Bhagwat $^{1} \cdot$ Renu Suthar $^{1}\left[\right.$ (]) Kapil Goyal $^{2} \cdot$ Suresh Kumar Angurana ${ }^{1} \cdot$ Sameer Vyas $^{3}$. \\ Sourabh Dutta ${ }^{1}$
}

Received: 4 September 2021 / Accepted: 27 October 2021 /Published online: 24 January 2022

(c) Dr. K C Chaudhuri Foundation 2022

To the Editor: Neurological complications related to SARS$\mathrm{CoV}-2$ are increasingly recognized. Encephalopathy, meningoencephalitis, stroke, seizures, Guillain-Barré syndrome, and acute disseminated encephalomyelitis (ADEM) are the most frequent neurological complications of COVID19 [1, 2]. Here, we report an unusual case of acute hemorrhagic leukoencephalitis (AHLE) secondary to COVID-19 coinfection.

An 8-y-old girl presented with fever, headache, left focal seizures followed by encephalopathy for $5 \mathrm{~d}$. She was admitted to a peripheral hospital where lumbar cerebrospinal fluid (CSF) analysis revealed 740 cells, (94\% neutrophils), $10 \mathrm{mg} / \mathrm{dL}$ glucose, and $224 \mathrm{mg} / \mathrm{dL}$ protein, and gram-positive cocci in gram stain. MRI brain showed multifocal discrete and coalescing lesions involving cerebral white matter and deep gray matter with diffusion restriction and interspersed microhemorrhages suggestive of AHLE (Supplementary Fig. S1). Her nasopharyngeal swab RT-PCR was positive for SARS-CoV-2. She was admitted in an unconscious state and required intubation, ventilation, antibiotics, and antiraised intracranial pressure measures. Investigations showed anemia $(\mathrm{Hb}-9.2 \mathrm{~g} / \mathrm{dL}$ ) and thrombocytopenia (platelets $18000 / \mu \mathrm{L})$, elevated C-reactive protein (CRP $141 \mathrm{mg} / \mathrm{dL})$ and D-dimer levels $(7014 \mathrm{ng} / \mathrm{mL})$. Blood and CSF cultures were sterile, and scrub typhus serology was negative. She had progressive neurological deterioration and succumbed to the illness.

Neurological complications associated with COVID-19 are immune-mediated in nature, where MRI brain shows focal or confluent hyperintensities involving white matter with or without diffusion restriction and contrast enhancement [3]. Extensive necrotizing myelitis with microhemorrhages and

\section{Renu Suthar}

drrenusuthar@gmail.com

1 Department of Pediatrics, Advanced Pediatric Center, PGIMER, Chandigarh 160012, India

2 Department of Virology, PGIMER, Chandigarh, India

3 Department of Radiodiagnosis, PGIMER, Chandigarh, India diffuse leucoencephalopathy with multiple microhemorrhages have been described with COVID-19 [2, 4]. Four pediatric cases of COVID-19 coinfections with other bacterial and viral agent with an unusual fulminant course and death have been reported [2]. Development of neurological symptoms within 2 wk of SARS-CoV-2 exposure, markedly elevated CRP, D-dimer levels, and thrombocytopenia were pointers toward systemic features of COVID-19 in the index case. The presence of SARS-CoV-2 coinfection contributed to extensive AHLE secondary to synergistic immune dysregulation.

Supplementary Information The online version contains supplementary material available at https://doi.org/10.1007/s12098-021-04029-4.

\section{Declarations}

Conflict of Interest None.

\section{References}

1. Rogers JP, Watson CJ, Badenoch J, et al. Neurology and neuropsychiatry of COVID-19: a systematic review and metaanalysis of the early literature reveals frequent CNS manifestations and key emerging narratives. J Neurol Neurosurg Psychiatry. 2021;92:932-41.

2. Lindan CE, Mankad K, Ram D, et al. Neuroimaging manifestations in children with SARS-CoV-2 infection: a multinational, multicentre collaborative study. Lancet Child Adolesc Health. 2021;5:167-77.

3. Siracusa L, Cascio A, Giordano S, et al. Neurological complications in pediatric patients with SARS-CoV-2 infection: a systematic review of the literature. Ital J Pediatr. 2021;47:123.

4. Agarwal S, Jain R, Dogra S, et al. Cerebral microbleeds and leukoencephalopathy in critically ill patients with COVID-19. Stroke. 2020;51:2649-55.

Publisher's Note Springer Nature remains neutral with regard to jurisdictional claims in published maps and institutional affiliations. 